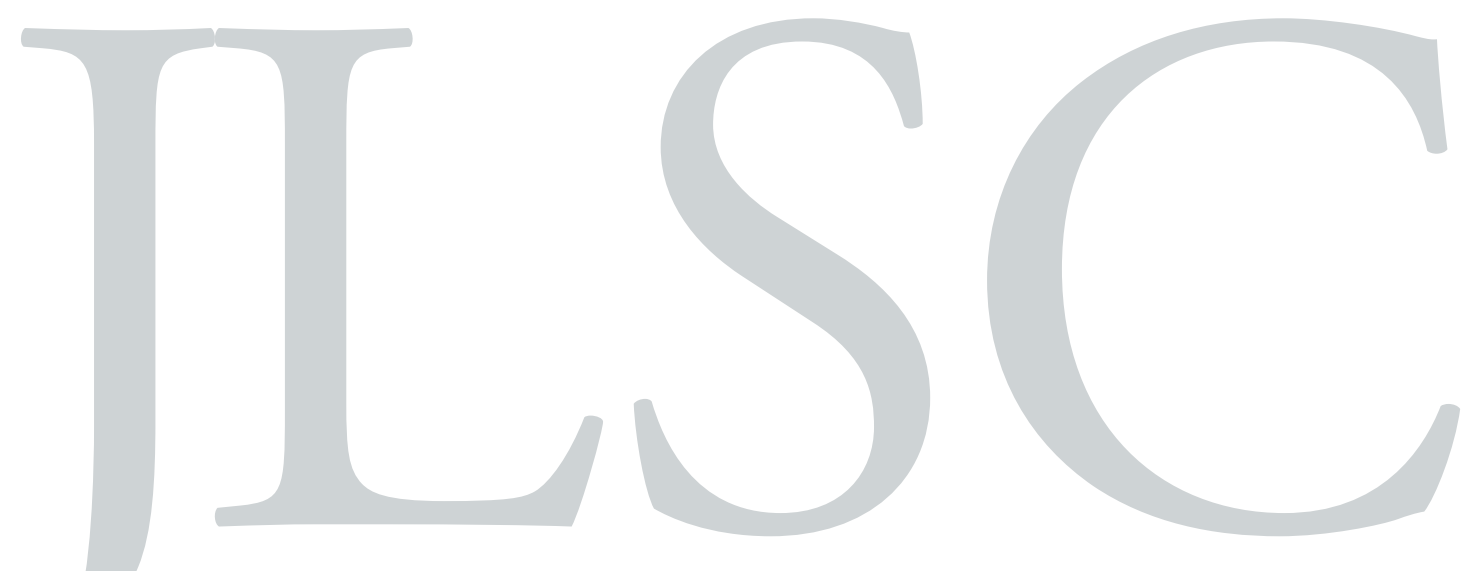

Volume 9, General Issue (2021)

\title{
Scholarly Communication Outside the R1: Measuring Faculty and Graduate Student Knowledge and Interest at a Doctoral/ Professional University
}

Erin Elizabeth Owens \& Tyler Manolovitz

Owens, E.E., Manolovitz, T. (2021). Scholarly Communication Outside the R1: Measuring Faculty and Graduate Student Knowledge and Interest at a Doctoral/Professional University. Journal of Librarianship and Scholarly Communication, 9(General Issue), eP2413. https://doi.org/10.7710/2162-3309.2413 


\title{
Scholarly Communication Outside the R1: Measuring Faculty and Graduate Student Knowledge and Interest at a Doctoral/ Professional University
}

\author{
Erin Elizabeth Owens \\ Professor, Access Services Coordinator \& Scholarly Communications Librarian, Sam Houston State University \\ Tyler Manolovitz \\ Clinical Assistant Professor, Research/Instruction Librarian, Sam Houston State University
}

INTRODUCTION This study explores the baseline knowledge and interest of faculty and graduate students at a Carnegie-classified Doctoral/Professional University regarding different components of scholarly communication. METHODS A survey was developed to inquire about such topics as scholarly research, scholarly publishing, access to research, copyright, measuring impact, promoting research, and openeducational resources. Responses more significantly represented the humanities and social sciences versus the natural and applied sciences. RESULTS \& DISCUSSION Results showed some hesitancy in embracing the open access (OA) publishing model, especially the use of article processing charges (APCs). Faculty largely collect original data and believe public access to original data is important, but this varies by college and includes almost one-fourth of faculty who do not feel that sharing data is important. The areas in which respondents expressed the highest level of knowledge correlate directly with the areas in which respondents expressed the most interest in professional development. Preferences in professional development modality were split between virtual and in-person sessions. With virtual sessions specifically, graduate students prefer synchronous sessions while faculty prefer pre-recorded sessions. CONCLUSION Respondents were generally aware of the library's current scholarly communications services, but additional promotion and marketing is still needed, especially for colleges with the lowest areas of engagement.

Received: 02/01/2021 Accepted: 04/06/2021

Correspondence: Erin Elizabeth Owens, Newton Gresham Library, Sam Houston State University, SHSU Box 2179 , Huntsville TX 77341, eowens@shsu.edu 


\section{IMPLICATIONS FOR PRACTICE}

1. Many faculty members, especially in the social sciences, still inherently mistrust article processing charges (APCs) as "pay to play," and academic librarians can provide essential interventions to educate faculty on the benefits of open-access publishing, the nature of APCs, options for funding, and methods for targeting APC-free journals.

2. Open sharing of data is highly valued in many disciplines, but that value may not be translating into that discipline's policies or researcher behaviors, possibly related to different disciplinary understandings of data. Academic librarians can provide education and support services to help bridge the gap and increase researcher understanding of why and how to share data.

3. Researchers are most interested in further professional development in the areas of scholarly publishing and access to research, even though they also rank these as the areas of their highest existing knowledge. Academic librarians can strategically incorporate critical topics of low knowledge and low interest—such as copyright—into training sessions on higher-interest topics.

4. Graduate students have high interest in receiving scholarly communications-related professional development and are especially interested in live, face-to-face sessions.

5. Additional promotion and marketing activities are needed to increase faculty and graduate student awareness of scholarly communications services provided by the academic library and the direct, "value-added" benefits of leveraging these services.

\section{INTRODUCTION}

Scholarly communication encompasses several different concepts that contribute in different ways to the quality, integrity, and success of academic research. Libraries and librarians work to promote and encourage scholarly communication among their faculty and graduate student population, but not much is known about researcher baseline knowledge of, and interest in, the different facets of scholarly communications, particularly in terms of a university's Carnegie Classification.

The setting for this study is Sam Houston State University (SHSU), a 20,000-student Carnegie-classified Doctoral/Professional University (D/PU) located in a small town in Texas. Unlike R1 Doctoral universities that are highly research-driven, SHSU strives for a balance between research activities and excellence in teaching. Because of this research/ teaching balance, there is a need to know how much D/PU faculty, and by extension the graduate students they teach, understand about the scholarly research lifecycle and where they do or do not have interests in further developing their knowledge. Understanding the baseline knowledge and interest of faculty and graduate students regarding scholarly communication at SHSU will help to suggest what services and promotion academic libraries at 
other D/PUs should emphasize and how those services might differ from academic library services at R1 institutions, particularly in the humanities and social sciences, where many issues such as open data mandates have not yet become as familiar as they are in the natural and applied sciences.

\section{LITERATURE REVIEW}

An overview of past research finds informative partial models, but ultimately yields no comprehensive baseline for the knowledge and interest in an array of scholarly communications topics among faculty at a D/PU.

Some studies did seek to establish knowledge baselines, most notably DeSanto and Nichols (2017). However, much of the existing literature focused on faculty attitudes and practices in scholarly communications without establishing baseline measures of researchers' knowledge or understanding of concepts; see, for example, Lercher, 2008; Abrizah, 2009; Kocken and Wical, 2013; Rodriguez, 2014; Wolff-Eisenberg, Rod, and Schonfeld, 2015. Without understanding baseline knowledge, it can be difficult to know whether a researcher developed a particular practice knowingly and purposefully or only because alternative options were unknown.

Although a few studies encompassed a wider breadth of concepts within the scholarly communications lifecycle (notably the Ithaka $S+R$ studies by Wolff-Eisenberg, Rod, and Schonfeld, 2015, and Blankstein and Wolff-Eisenberg, 2019), most focused on just one or two concepts within scholarly communications. For example, Abrizah (2009) and Lercher (2008) focused specifically on digital repositories. Creaser (2010) and Kocken and Wical (2013) also focused on repositories, but incorporated knowledge of open-access publication as well. Faculty knowledge and perception of OA publishing was the sole focus for Peekhaus and Proferes (2015), Rodriguez (2014), Mischo and Schlembach (2011), Lwoga and Questier (2014), and Gaines (2015). Research metrics has been another popular topic of focus for studies of faculty awareness and understanding; see for example Vinyard and Colvin (2018), Thuna and King (2017), DeSanto and Nichols (2017), and Sutton, Miles, and Konkiel (2018). Meanwhile, Diekema, Wesolek, and Walters (2014), Van Tuyl and Michalek (2015), and Weller and Monroe-Gulick (2015) focused only on faculty knowledge and skills pertaining to research data management. Tran and Lyon (2017) explored faculty knowledge and use of author identifiers, researcher networking systems, and social media platforms.

Furthermore, many past studies focused on specific researcher demographics; for example, the University of California's Report on Faculty Attitudes (2007) and Harley et al. (2010) 
focused on elite R1 institutions; Peekhaus and Proferes (2015) focused only on faculty in Library and Information Sciences; and Thuna and King (2017) surveyed only "senior" researchers, 5+ years post-tenure. Vinyard and Colvin (2018) did evaluate faculty at a Doctoral/Professional institution, more comparable to SHSU, but focused only on one school within the university, in which faculty worked almost exclusively with undergraduate students; additionally, with only 66 responses, the sample size was small. However, they did find that the D/PU faculty were less aware of journal prestige than suggested by the findings of the Ithaka $S+R$ survey, supporting the belief that R1 and D/PU faculty will differ in terms of knowledge and needs for research support. Laughtin-Dunker's study in 2014 pursued a goal that significantly parallels that of the current study-and their published article is an excellent case study of a so-called "failed survey" with many lessons of value-but their sample size of only 20 respondents makes the resulting data less than conclusive.

Finally, many past studies have focused primarily on faculty without also considering graduate students as a researcher population needing scholarly communications services from academic libraries. Most notably, Weller and Monroe-Gulick (2015) made a point to survey graduate students alongside faculty; they found that graduate students expressed more need for help with data management plans than did faculty, with implications for targeting library educational efforts.

Our present study builds on existing literature by collecting baseline measurements of researcher knowledge and interest in a wide breadth of scholarly communications concepts in order to determine where library research support efforts should strategically focus. Additionally, this study seeks to expand existing data in this area by focusing on a Carnegie-classified D/PU; by inviting participation from graduate students, adjunct faculty, and visiting faculty, in addition to traditional tenured and tenure-track faculty; and by broadly including social sciences and humanities rather than focusing on the hard sciences and business fields.

\section{METHODOLOGY}

Initially the principal investigator sought pre-existing survey instruments, which might be adopted for this study. The Opportunity Assessment Instrument (Van Orsdel, 2007) was discovered and evaluated but ultimately rejected; it was designed more for a librarian to complete when assessing an academic department, and while it would provide useful metrics on departmental behavior, it did not measure individual knowledge and interest, which was the focus of the current study. 
The principal investigator instead generated a first draft of a new survey instrument. Workshopping with co-investigators resulted in a revised second draft. This was forwarded to staff in The Graduate School who had agreed to partner with the researchers in this effort; based on their experience working with the school's graduate population, they provided strategic feedback intended to streamline the survey instrument and to help increase the likely response rate. In particular, The Graduate School recommended that certain questions be excluded for graduate students, such as existing knowledge of scholarly communications concepts, collection and publication of research data, and OA publishing; they felt the knowledge and experience necessary for these questions was lacking, such that including the questions would make the survey longer and more overwhelming with a negative impact on survey completion. Implementing The Graduate School's feedback resulted in a third and final draft instrument, which—after being approved by the Institutional Review Board-was then pilot-tested with a sample of graduate students. Following the positive results of this pilot-testing, the survey was released publicly to all graduate students and faculty members of all ranks across campus. The survey can be viewed online at https://hdl. handle.net/20.500.11875/2945.

Thanks to the staff in The Graduate School, a survey invitation was emailed to all masters and doctoral students. However, due to some specific campus restrictions regarding mass emails, promoting the survey's availability to faculty posed a greater challenge. An advertisement ran in seven weekly installments of a digital newsletter from the Office of Academic Affairs. Subject liaison librarians assisted the researchers by emailing personal invitations to complete the survey to the faculty in their assigned subject areas. Print flyers were hand-delivered to the administrative offices of every academic department on campus, with requests for administrative assistants to post them near faculty mailboxes or in faculty breakrooms. Finally, flyers were displayed in several prominent locations within the library. All promotion included information about the opportunity for survey respondents to opt into a drawing for one of three prizes.

Survey responses were collected in the Qualtrics survey software for just over 7 weeks, after which time the survey instrument was closed and the prize drawing was completed. Settings were employed to anonymize responses so that all identifying information (including IP addresses) was omitted from the data recording; optional prize drawing entries were stored separately from survey responses so that an individual's contact information could not be traced back to their answers. Based on the survey flow constructed in Qualtrics, ineligible and incomplete responses were filtered out of the final dataset. Finally, demographic data describing the entire faculty population was requested from the appropriate campus office and compared to respondent demographics in order to determine to what extent the respondents were or were not representative of the campus. 


\section{RESULTS}

The potential respondent pool consisted of 1,047 faculty members and 2,531 graduate students, for 3,578 possible participants altogether. A total of 174 completed and eligible responses yielded a response rate of 5\%; respondents included 63 faculty members and 111 graduate students (65 Masters and 46 Doctoral). Multiple colleges were represented in this survey, though overall social sciences were significantly more represented than the natural and applied sciences; respondents were affiliated with the Colleges of Education 32.2\%; Criminal Justice 20.7\%; Humanities and Social Sciences 19.0\%; Science and Engineering Technology 13.8\%; Fine Arts and Mass Communication 6.3\%; Health Sciences 3.4\%; Business Administration 1.7\%; Library 0.6\%; and Other (without specification) $2.3 \%$.

Survey respondents were predominately female $68.0 \%$ versus $30.8 \%$ male and $1.2 \%$ preferring not to answer; non-binary was also provided as an option but received zero selections. The skew towards female resembled that in the total campus population during the same time period (Spring 2019 semester), in which faculty members were 51.2\% female and $48.8 \%$ male while graduate students were $67.4 \%$ female versus $32.6 \%$ male. It is unclear whether the higher representation of female respondents reflects the campus demographics, a greater involvement of females on campus in research activities, a greater willingness of females on campus to participate in the survey, or some combination of factors.

Younger respondents, including those new to a post-graduate academic career, made up most of the population. Respondents age 21-30 made up the largest demographic at $39.1 \%$, and those working 2 years or less accounted for $53.5 \%$. When broken down by faculty versus graduate students, results show that the largest group of faculty members were aged 31-40 (33.3\%) while graduate students heavily skewed to the 21-30 age range (57.7\%). Based on this data, the typical respondent was often female and an early-career researcher. Keeping this in mind is helpful when analyzing the rest of the data.

In looking at the preferred publication format, more total respondents expected to publish their scholarly research primarily in journal articles (69.5\%). Other responses included books and journal articles equally (14.9\%), books (4.0\%), or something else, such as creative scholarship, presentations, patents, etc. (1.2\%). Presumably because of the relatively high number of early-career researchers, $10.3 \%$ were unsure of their most likely publication medium. As expected, unsure responses were much more prevalent in graduate students $(15.3 \%)$ than faculty $(1.6 \%)$, revealing the impact of increased knowledge and experience on publishing expectations. 
In one section of the survey, all respondents were asked about the level of interest in professional development or training in several areas: scholarly research, scholarly publishing, access to research, copyright, measuring impact, promoting research, and open educational resources (OER). Table 1 details the descriptions of these topical areas as they were provided to participants. Respondents expressed moderate or high-level interest in many areas, but the most popular overall were scholarly publishing $(58.1 \%$ reporting high interest) and access to research $(53.5 \%$ reporting high interest). Copyright and measuring impact were the least attractive options with only $29.3 \%$ and $32.2 \%$ respectively reporting high interest.

\begin{tabular}{ll} 
Topic Area & Description \\
\hline Scholarly Research & $\begin{array}{l}\text { e.g., reference management software, data management plans, open data } \\
\text { mandates, etc. }\end{array}$ \\
\hline Scholarly Publishing & $\begin{array}{l}\text { e.g., evaluating journal quality, peer review, predatory publishing, OA } \\
\text { publishing, etc. }\end{array}$ \\
\hline Access to Research & e.g., publishing models, OA publishing mandates, repositories, etc. \\
\hline Copyright & $\begin{array}{l}\text { e.g., fair use, author's rights, negotiating contracts, Creative Commons } \\
\text { licenses, article manuscript versions, etc. }\end{array}$ \\
\hline Measuring Impact & $\begin{array}{l}\text { e.g., Impact Factor and other journal metrics, altmetrics, book metrics, } \\
\text { researcher metrics }\end{array}$ \\
\hline Promoting Research & $\begin{array}{l}\text { e.g., using metrics in CVs or grants, ORCID and other author identifiers, } \\
\text { researcher profiles, etc. }\end{array}$ \\
\hline Open Educational & e.g., finding, evaluating, adopting, remixing, etc. \\
Resources & \\
\hline
\end{tabular}

Table 1. Descriptions of topic areas provided to survey participants

In looking at only faculty, responses revealed a few key differences. Although scholarly publishing still had the most interest, only $46.0 \%$ expressed high interest (see Figure 1). In addition, access to research came in third overall $(39.7 \%$ high interest) behind openeducational resources (41.3\% high interest). Copyright (20.6\% high interest) and measuring impact (19.1\% high interest) still had the least amount of interest among the options. Graduate students revealed similar trends, but with even higher rates of reported interest: 64.9\% expressed high interest in scholarly publishing, and 61.3\% expressed high interest in access to research (see Figure 1). Copyright (34.2\% high interest) and measuring impact (39.6\% high interest) still ranked low, but represents marginally more graduate student interest than faculty interest. 


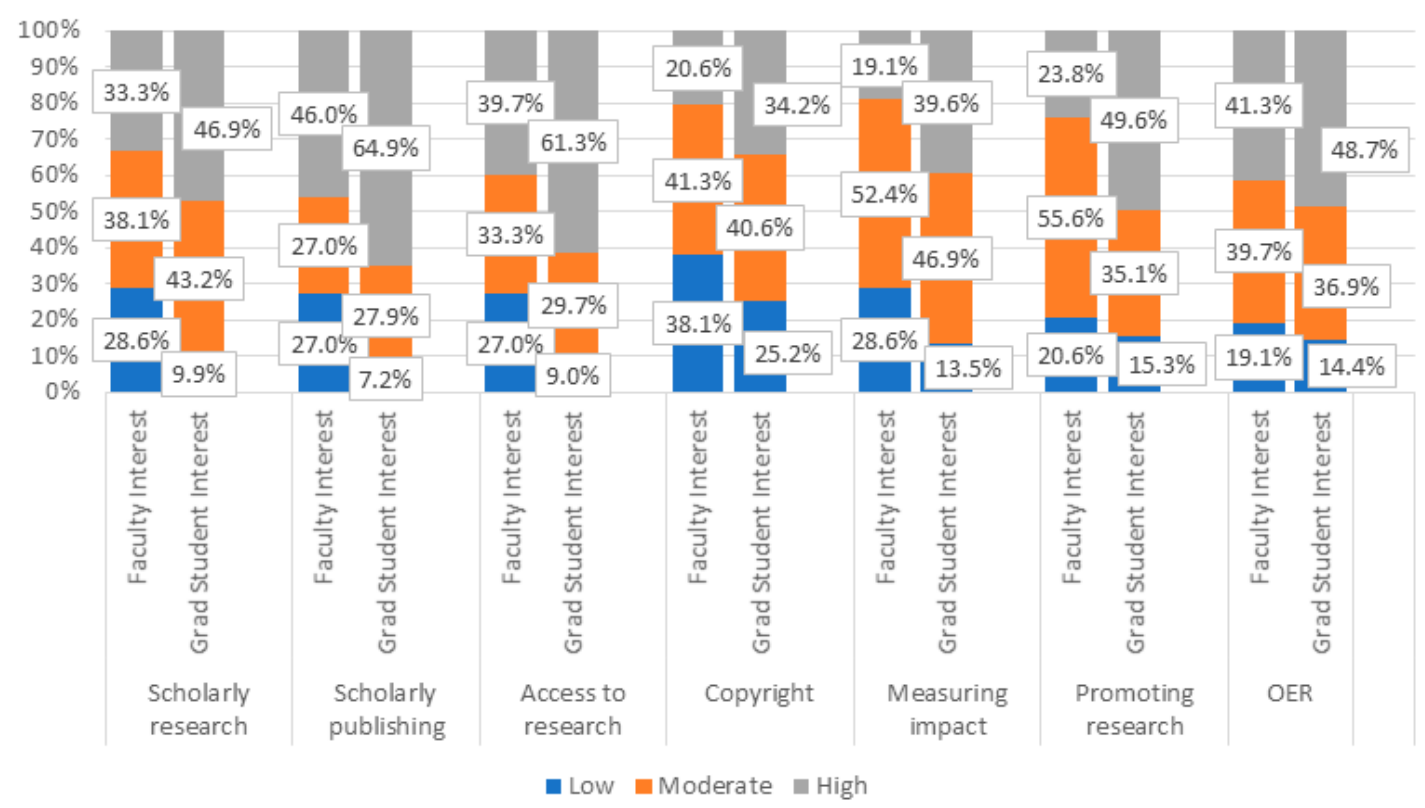

Figure 1. Faculty versus graduate student interest in scholarly communications topics.

Responses continued to echo similar patterns when faculty were asked about existing knowledge on these same topics (per feedback from The Graduate School, only faculty were asked about existing knowledge). The areas with highest existing faculty knowledge were also scholarly publishing $(54.1 \%)$ and access to research (39.3\%), with scholarly research also coming in at 39.3\% (see Figure 2). Overall, scholarly publishing, access to research, and scholarly research were the top three areas of existing knowledge for faculty members; in comparison, scholarly publishing and access to research also ranked in 1 st and 3rd place for faculty interest in professional development and training.

The two lowest areas of existing faculty knowledge were open educational resources and promoting research (with low knowledge reported by $36.1 \%$ for both). These same topics ranked in about the middle of the pack (3rd and 5th respectively) when asked about professional development/training interest. Taken all together, this data indicates that the topics with low knowledge were not necessarily the areas in which respondents most preferred to gain more knowledge. 


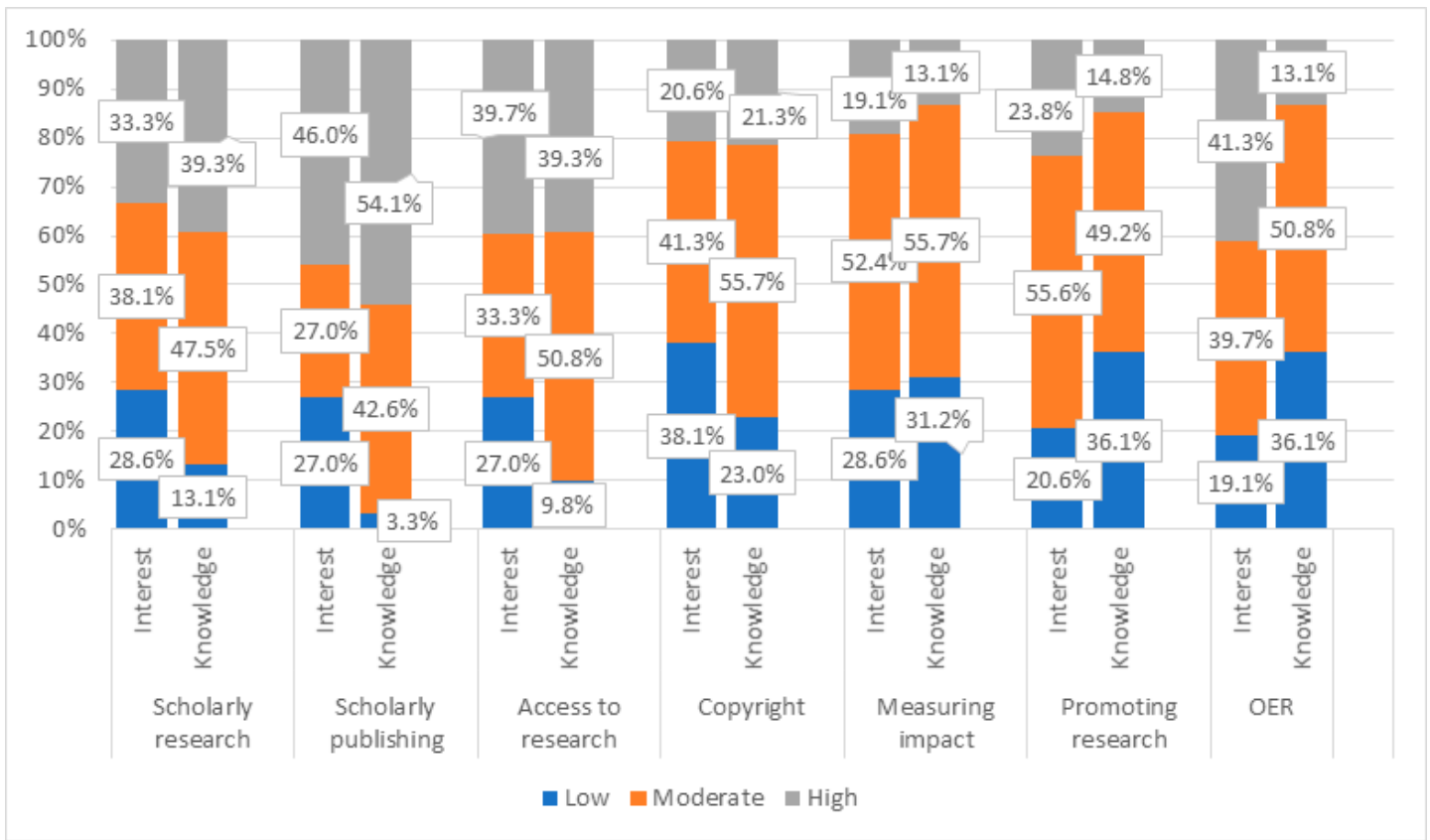

Figure 2. Faculty interest versus existing knowledge in scholarly communications topics

When asked about preferred methods of attending professional development/training sessions, all respondents showed a slight preference for virtual training (51.5\%) versus in-person $(45.8 \%)$. When broken down into more detailed options, the greatest preference was for in-person sessions on the main university campus (32.9\%), pre-recorded virtual sessions (26.7\%), and live-streaming virtual sessions $(24.9 \%)$. The largest groups of both faculty $(35.0 \%)$ and graduate students $(31.8 \%)$ indicated a desire to attend in-person training sessions on the main campus. Smaller groups were interested in live virtual training $(19.7 \%$ of faculty, $27.7 \%$ of graduate students) or pre-recorded virtual training $(23.1 \%$ of faculty, $28.6 \%$ of graduate students). Additionally, $17.1 \%$ of faculty and $10.6 \%$ of graduate students reported an interest in live training at the branch campus; $5.1 \%$ of faculty and $0.5 \%$ of graduate students indicated no interest in attending training; $0.9 \%$ of graduate students requested "other" options.

When asked how they would prefer to be notified of professional development opportunities, a simple email was the much-preferred choice with $42.9 \%$ overall $(50.5 \%$ of faculty and $39.6 \%$ of graduate students). This result is of particular interest due to indications from university administration that both employees and students receive too much email and would prefer to receive less. The next most popular choice was an announcement in an existing university newsletter, such as those sent out by the Office of Academic Affairs 
or the Professional and Academic Center for Excellence; this was selected by $18.1 \%$ overall (16.5\% of faculty and $18.8 \%$ of graduate students). Other proposed contact methodssuch as paper flyers, general campus or library social media, or dedicated opt-in email or social media specifically for scholarly communications - received very low interest, though it may be worth noting that faculty had somewhat more interest in paper flyers $(9.2 \%)$ while graduate students had somewhat more interest in promotion via campus social media $(14.3 \%)$.

In looking at data collection, most faculty $(80.3 \%)$ indicated that they collect original data in their research, and $73.8 \%$ saw Extreme or Moderate Importance in original research data in their discipline being publicly available (per feedback from The Graduate School, only faculty were asked about data collection and open-access publishing). Interestingly, though, a vast majority $(79.6 \%)$ were not required by mandates from grant-funding agencies to provide OA to their data. The researchers received these results with curiosity. With so many respondents believing that their disciplines value publicly accessible data, one might expect that more than $10.2 \%$ of researchers would be required to provide such access (another $10.2 \%$ were unsure). However, we should also note that behavior is not necessarily dependent on requirements, since some researchers may choose to share data without a mandate. Additionally, this apparent conflict is tempered by the very small counts of participants (10 or less) once they are broken into groups by college.

If we dig deeper into these numbers, we find that despite most faculty expressing some importance in providing public access to data, only 32.8\% believed it is Extremely Important; $41.0 \%$ considered it Moderately Important, and another $26.2 \%$ said it was Not Important. These numbers vary greatly depending on the college. At one end of the spectrum, $100 \%$ of faculty in the Colleges of Business, Criminal Justice, and Health Sciences indicated that public data was either Extremely or Moderately Important. This contrasts with the other end of the spectrum, where $55.6 \%$ of faculty in the College of Education states that public data was Not Important.

When faculty were asked about OA publishing, 34.4\% were extremely likely to publish an article as OA if their institution or grant paid for any article processing charges (APCs). On the flip side, $63.9 \%$ would be very unlikely to pay such fees on their own (see Figure 3). One might expect that individuals would not wish to pay these fees out of pocket. However, the low number of respondents interested in having them paid institutionally may indicate a potential mistrust or misunderstanding of paying to publish, regardless of who pays the fees. In one open comment, a respondent indicated their department does not count "paid" articles for tenure. Although OA publishing has made great strides, it still isn't being fully understood or embraced by our faculty. Many faculty participants did respond 
very positively $(24.6 \%)$ or somewhat positively $(29.5 \%)$ to OA publishing, but that leaves $43.7 \%$ with either no opinion, somewhat negative feelings, or very negative feelings. Different colleges, though, do appear to perceive open-access publishing differently. Some respondents from the College of Business Administration (33.3\%) and the College of Health Sciences $(25.0 \%)$ did indicate being either very likely or somewhat likely to pay an APC on their own, as compared to the College of Criminal Justice, College of Education, and the College of Fine Arts and Mass Communication, which had zero respondents expressing interest. Some colleges skewed quite heavily against paying these charges, with the College of Humanities and Social Sciences (75\%) and College of Education (100\%) responding as very unlikely. Although these numbers are limited, they do hint at a disciplinary difference in perception of OA publishing.

Faculty: How likely would you be to publish an article open access if...

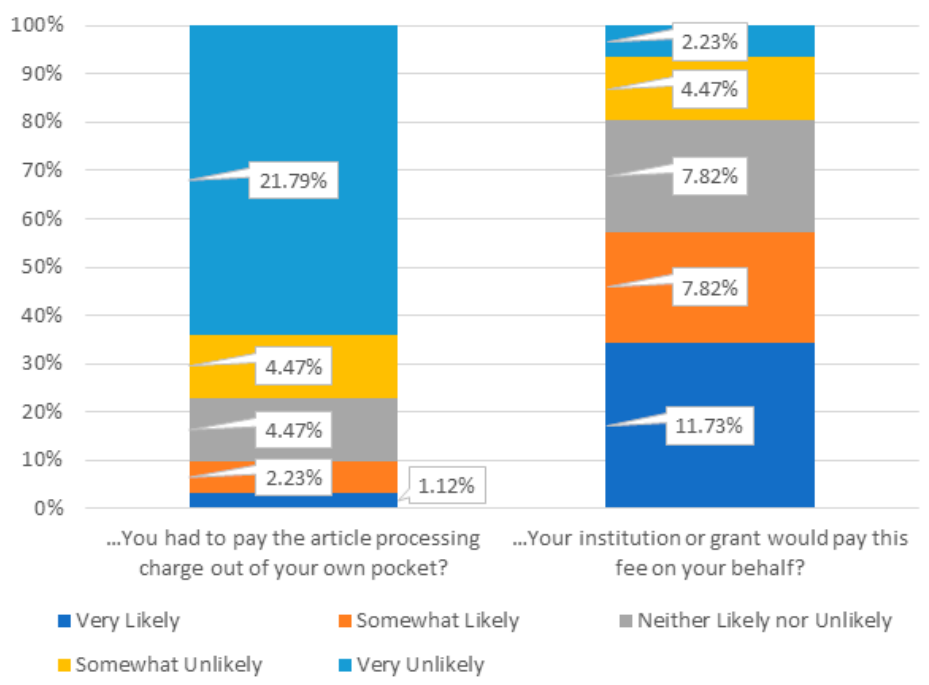

Figure 3. Faculty Likeliness to Publish OA with External Funding or Self-Funding

Another area of the survey asked about the level of current engagement with, and awareness of, three different scholarly communication resources within the library: an online educational guide (in LibGuides) about topics covered in the survey; communication with the Scholarly Communications Librarian regarding topics covered in the survey; and communication with the departmental Subject Librarian regarding any topics. In looking at the online educational guide, $39.1 \%$ of all respondents were unaware of the resource, although 
$33.3 \%$ had engaged frequently or occasionally. This leaves $27.6 \%$ who were aware of the resource but had not engaged (see Figure 4). When asked about communicating with the Scholarly Communications Librarian regarding topics covered in the survey, $34.5 \%$ reported being unaware of the service, $24.1 \%$ reported frequent or occasional engagement, and $41.4 \%$ were aware but had not engaged. When asked about communicating with their department's Subject Librarian regarding any topics, $20.1 \%$ reported being unaware, $44.3 \%$ reported frequent or occasional engagement, and $35.6 \%$ were aware but had not engaged (see Figure 4).

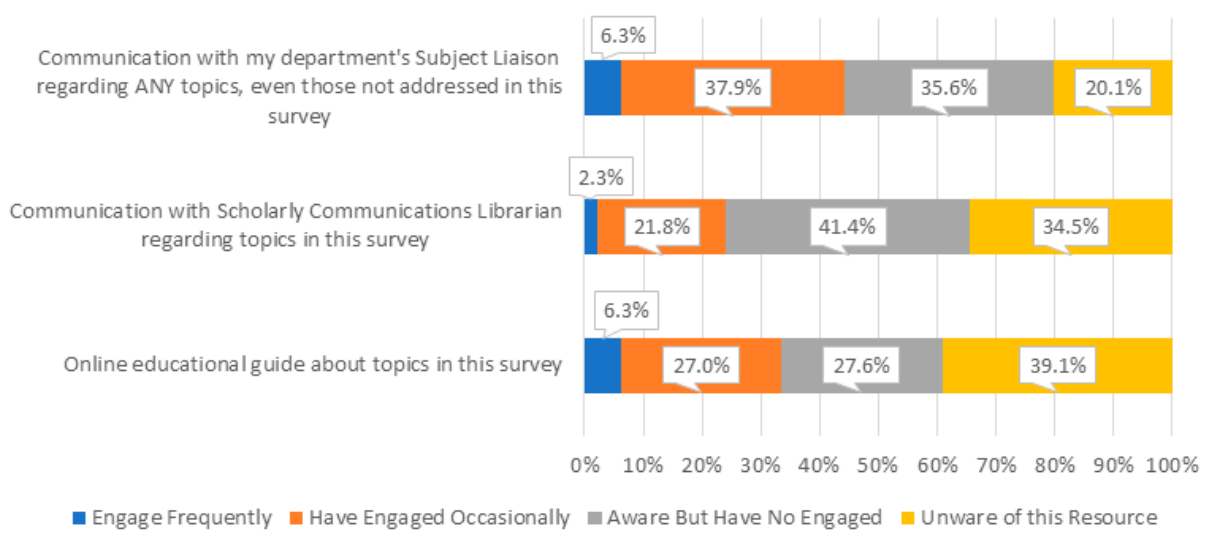

Figure 4. Current Faculty and Graduate Student Engagement with Library Resources

When analyzed by college, between $30 \%$ and $50 \%$ of respondents in all colleges were unaware of the educational guide, although some more than others. In the College of Health Sciences, $50.0 \%$ were unaware, and in the College of Fine Arts and Mass Communication, $45.5 \%$ were unaware, as opposed to $33.3 \%$ in the College of Business Administration and the College of Humanities and Social Sciences.

After taking this survey, interest in future engagement about these topics was much higher: $64.4 \%$ reported being extremely likely or somewhat likely to engage with the online guide, $56.9 \%$ reported being extremely likely or somewhat likely to engage with the Scholarly Communications Librarian, and $66.7 \%$ reported being extremely likely or somewhat likely to engage with the department's subject librarian (see Figure 5). Some stark differences appeared between academic colleges. In the College of Health Sciences, zero respondents said they were extremely likely to engage with the online guide in the future, but $83.3 \%$ were somewhat likely to do so (the remaining $16.7 \%$ were extremely unlikely). The College of Education, meanwhile, was more positive, with $32.1 \%$ extremely likely; $37.5 \%$ somewhat 
likely; and only $7.1 \%$ extremely unlikely to engage with the guide in the future. The Colleges of Health Sciences and Education were optimistic about future engagement with the Scholarly Communications Librarian, with $66.7 \%$ and $62.5 \%$ respectively indicating they were either extremely likely or somewhat likely to leverage this service. Sizable majorities in all colleges were extremely likely or somewhat likely to engage with their subject librarian in the future. Faculty and graduate students also expressed similar interest in future engagement about these topics: $61.9 \%$ of faculty and $65.8 \%$ of graduate students reported being extremely likely or somewhat likely to engage with the online educational guide, $54.0 \%$ of faculty and $58.6 \%$ of graduate students reported being extremely likely or somewhat likely to engage with the Scholarly Communications Librarian, and 69.9\% of faculty and 64.9\% of graduate students reported being extremely likely or somewhat likely to engage with the department's subject librarian.

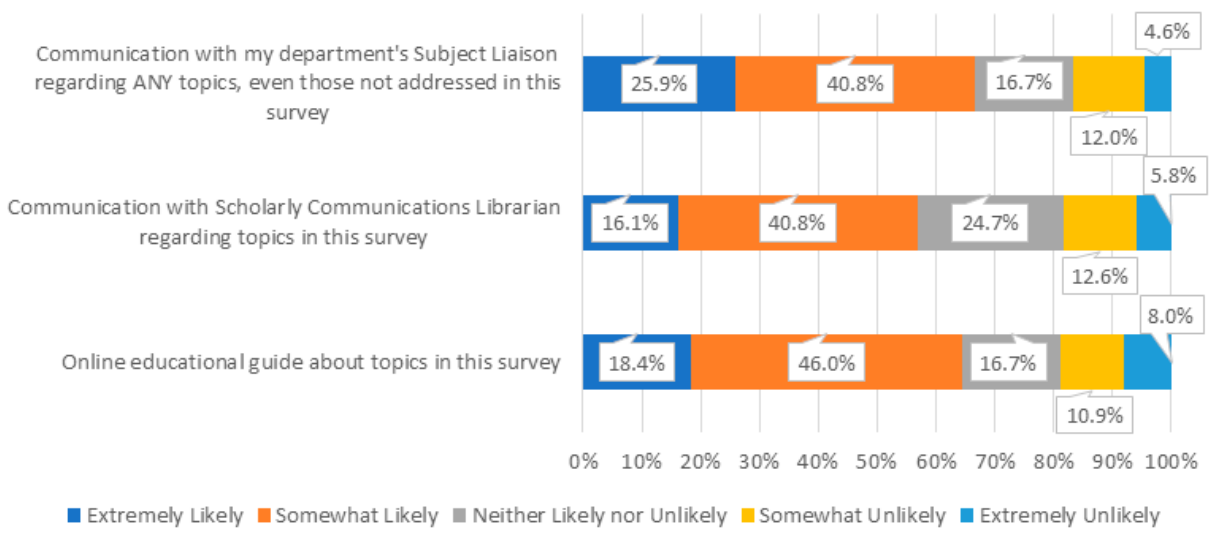

Figure 5. Likeliness for Future Faculty and Graduate Student Engagement with Library Resources

\section{DISCUSSION}

Several noteworthy themes and questions arose from analyzing the survey response data, which can inform the library's scholarly communication agenda going forward.

\section{Existing Knowledge Versus Interest in Professional Development}

Some members of the research team expected that respondents would demonstrate interest in increasing their understanding of areas where they indicated low existing knowledge: for example, if a faculty member recognizes that they currently know little about copyright, then they might express an interest to develop this area of weakness and fill in the gaps they have perceived in their own knowledge. However, in reality, the opposite was discovered. 
The areas in which faculty expressed the highest perceived existing knowledge were also the areas where they were most interested in additional professional development. At the same time, the topics ranked lowest for perceived existing knowledge were also ranked of least interest for development. The sheer lack of interest in a specific topic may be the primary variable at play: if a faculty member is not and has never been interested in this subject, then they would not have put forth past time or effort to gain knowledge, and they would not be interested in exerting that effort in the future either.

This contrast between the respondents' existing knowledge versus interest also highlights a clear disconnection between user interest and librarian perception of importance. To examine one case in point: Scholarly communication librarians often encounter faculty questions about, or inappropriate faculty behavior regarding, copyright. ${ }^{1}$ As a result, they understandably perceive copyright education as a needed and valuable component of campus outreach. However, when faculty and graduate students respond with such low interest in this training - despite their admitted lack of existing knowledge — then librarians may be forced to rethink how they integrate and promote copyright as part of their broader training agenda.

The survey responses suggest that advertising a session focused directly on copyright would be unlikely to attract many attendees. Instead, scholarly communications librarians should strategize ways to integrate fundamental copyright and fair use concepts into training sessions on topics of high user interest. Respondents to this survey expressed the most interest in professional development in the area of Scholarly Publishing (e.g., evaluating journal quality, peer review, predatory publishing, OA publishing, etc.). With strategic planning, a training session on open-access publishing could easily address some aspects of traditional copyright versus open licensing and a discussion of authors' rights, while a session on evaluating journal quality could incorporate additional discussion on copyright as it pertains to reading or negotiating a journal's publication policies or a publishing contract. Other topics with lower user appeal, which a librarian perceives as nevertheless important and needed in their user population, could similarly be incorporated as bite-size pieces of training incorporated into sessions on topics with higher audience draw.

\section{Training Preferences}

Live, in-person training was the preferred format by both graduate students and faculty, though virtual training also had a fair share of interest. (In discussing live preferences, it should be noted that this survey took place prior to the COVID-19 pandemic.) In the online format, graduate students showed a greater preference for live streaming, while fac-

${ }^{1}$ See, for example: Graveline, 2010; Gadd, 2017; and Jamali, 2017. 
ulty preferred pre-recorded sessions. Recognizing the different pressures placed on faculty versus student schedules from day to day, this discrepancy is unsurprising to the researchers. However, the researchers feel some skepticism about both groups' expressions of intent to watch pre-recorded sessions and wonder whether this ideal intent would actually manifest in action. The library must remain open to exploring these new routes, but tracking usage is essential so that offerings can be adapted as warranted going forward. Additionally, the small portion of participants who expressed interest in attending live sessions on the university's branch campus, although not representing a stunning number, nevertheless indicates a population need which has not previously been supported. Institutions with multiple library branches or multiple campuses should consider whether live sessions are scheduled across these locations in a balanced way to reach all users.

Respondents in both groups showed a preference for learning about these training opportunities via direct email communication. This poses difficulties on a campus where certain measures have been put in place to restrict mass emails. It also suggests that launching an opt-in email subscription service for updates from the Scholarly Communication Librarian might be an avenue to explore, but marketing the existence of that opt-in service would potentially face the same obstacles as mass emails. Existing campus e-newsletters from departments such as the Office of Academic Affairs and the Professional and Academic Center for Excellence were the second most highly ranked communication mechanism (despite receiving less than half the responses received for email), and they represent a much simpler means of promoting training opportunities. However, communication formats, which are not directly controlled by the library can pose their own challenges, which librarians must thoughtfully prepare to manage. For example, each campus e-newsletter mandates its own format for content submissions and follows its own distribution schedule-some weekly, some monthly, some quarterly; additionally, with some newsletters, there is a delay between content submission and content publication. Therefore, promotion via these channels will require careful planning and scheduling that takes all the idiosyncrasies into account, and some outlets may be of less value if training events are not scheduled far enough in advance.

\section{Open Data}

When faculty were asked how important they felt it was in their discipline for researchers to make original research data publicly available, $23.9 \%$ of respondents indicated that they felt publicly sharing data was not important. This set of responses, albeit small, raised questions for the researchers. Some individuals may feel discomfort or intimidation about sharing their own data, but what might motivate them to believe that open sharing in general is not valuable? More disciplines have experienced increases in grant-funder mandates for data to be archived openly, especially since the Obama administration passed the Open Data Policy 
in 2013. ${ }^{2}$ Even more disciplines are benefitting from the use of open datasets, in applications ranging from geographic information systems (GIS) to text mining in literary studies. Additionally, open data sharing helps to improve credibility, objectivity, accountability, and reproducibility, all of which are components of the values of good science and scholarship. ${ }^{3}$ At least in part, a lack of robust knowledge could be to blame. When we examine how these "open data is not important" responders rated their own existing knowledge, 81.3\% of them indicated a Moderate or Low level of knowledge in Scholarly Research $(68.8 \%$ and $12.5 \%$, respectively), and $50.0 \%$ reported Low interest in training opportunities in this area. If these individuals self-report that they know little and are not inclined to learn more, that may be a factor in their viewing the topic as unimportant. Conversely, however, their perception of the topic as unimportant could be a factor influencing their lack of interest to learn more. Either way, a relationship may exist between their curiosity and the amount of value they place on the subject. Furthermore, they may feel some level of intimidation about learning more, which negatively colors their judgment. This study's data cannot draw conclusions on these theories, but they would be worth exploring more fully in later focus groups.

Discipline likely plays a factor. Although open data mandates are increasingly emerging across the disciplines, they are most common in the hard sciences, which were underrepresented in the survey's sample. One possible example of this disciplinary difference emerged when analyzing the details of these responses. About one-third of this respondent group was comprised of faculty in the College of Education. Within the context of their discipline, they may have mentally associated the idea of data with individual student data and felt concern about the idea of data sharing, related to the violation of ethics, privacy, and FERPA laws. Similarly, faculty in disciplines such as history, literature, and language may be unaccustomed to thinking of their work in terms of more scientific data collection; for example, if a researcher is analyzing a literary work, do they have a clear understanding of what comprises their dataset, how they could or would share that data, and what limits copyright would or might impose? Different disciplinary understandings of terminologywhether in the forms we have imagined here or others - may have affected the way in which some individuals responded to the question about the importance of sharing data openly. Finally, although this survey did not touch on the idea of researchers receiving credit for sharing data, that may present another barrier to sharing. The State of Open Data 2020

\footnotetext{
${ }^{2}$ Out of 162 funders detailed in the Sherpa Juliet database of funder mandates in 2020, 28\% (n 45) required open data and another 19\% (n 30) encouraged open data (data accessed by authors at https:// v2.sherpa.ac.uk/juliet/, June 5, 2020). In comparison, in 2015, there were "34 funders who require data archiving and 16 who encourage it" (Hahnel, 2015).

${ }^{3}$ See, for example, National Academies, 2017.
} 
report from Digital Science found that nearly $60 \%$ of respondents believed researchers "receive too little credit" for sharing data, down only slightly from 2019's survey (p. 14). The Scholarly Communications Librarian may be able to partially address this barrier at the institutional level and advocate for ways in which the tenure and promotion process, research awards, and so forth can acknowledge the benefits of shared data.

\section{Perception of Open-Access (OA) Publishing and Article Processing Charges (APCs)}

Responses regarding the payment of APCs somewhat matched expectations, that is, that faculty would rather their department or grant pay an APC than pay it themselves out of pocket. However, the data still reflect a great mistrust of paying, period, regardless of who funds the payment. No correlation was apparent between a negative perception of OA publishing and low existing knowledge in this area; additionally, the faculty with negative opinions were not characterized by any particular academic discipline, age, gender, length of research career, or other variables-however, given the dataset's overrepresentation of social sciences and underrepresentation of hard sciences, this may simply reflect an underlying unfamiliarity with APCs in some disciplines.

The researchers suspect a fundamental lack of understanding may play a role in some responses: some faculty may equate open-access publishing, especially when funded by APCs, to predatory publishing. Without expert training in the distinctions, one may mistakenly perceive that all OA publishing requires fee payments, and that all instances of fee payments for publication are inherently predatory. These faculty may be unaware that even legitimate scholarly publishers often charge APCs to make articles OA, while other OA journals do not charge APCs at all, so no direct correlation exists between fees and credibility.

One faculty respondent commented in an open-ended question that their department will not count "paid articles" towards tenure and promotion. It is unclear whether this specific department is just behind the curve on embracing open-access publishing, or whether a fundamental misunderstanding exists— - with this individual or their department-about the distinction between legitimate APCs versus predatory or vanity publishing fees. The need is clear for the library to open frank discussions with department chairs across campus to begin untangling threads of (mis) understanding and policy.

\section{Attitude towards Library as Professional Development Provider}

The researchers were encouraged by the finding that $60-80 \%$ of respondents were at least aware of all the library resources referenced in the survey: the online educational guide to research, the specialist librarian supporting scholarly communications, and the subject 
librarian. It is possible that this was skewed by self-selection bias, in the sense that the faculty and graduate students most aware of these resources may have been more inclined to respond to the survey invitation. Regardless, the remaining 20-40\% who were previously unaware of these resources - or possibly more, if we assume some skewing in the respondent pool-indicates that a significant amount of progress can still be made in promoting library support for scholarly research activities, with special focus on those colleges with particularly low awareness.

Strategies for promotion might include announcements in existing campus e-newsletters every month, quarter, or semester, in order to share a tip, insight, or recent event in scholarly communication news. This would allow for a planned, consistent, periodic reminder of the specialist librarian's presence, with that librarian listed as the contact point, and such announcements could include a standard "learn more" link to the library's online educational guide. Another promotion strategy might include working with the staff of The Graduate School on campus to integrate a link to the library's guide into the standard list of resources provided to graduate students. Similarly, a handout on library research services could be incorporated into the packet that each new faculty member receives during their faculty investiture. Based on responses regarding a preference for email communication, an opt-in email subscription list also seems like a potential candidate for promotional strategies to test. Workshops have been held sporadically in the past but need to be developed into a more consistent schedule and with expanded attendance options (branch campus, live virtual, on-demand recordings, etc.). The Scholarly Communications Librarian could also design a 6-to 8-week virtual event where participants sign up to build their scholarly researcher savvy through weekly tasks or challenges, as an alternative way to drive knowledge and engagement without tying participation to a specific time and place.

Overall, participants' intent to engage with the Scholarly Communications Librarian in the future seems promising. However, the variation in responses among academic colleges highlights the continued importance of the subject liaison's role: although some faculty will be comfortable reaching out to the specialist directly, other faculty will be better engaged through their familiar subject librarian liaison. Subject liaisons on this campus often have a graduate degree, or at least some amount of advanced coursework, in their assigned subject area and may be perceived by faculty in their area as a more knowledgeable peer, compared to the Scholarly Communications Librarian who may lack robust familiarity with their discipline. The Scholarly Communications Librarian will continue seeking ways to educate subject liaisons on relevant topics, in a "train the trainer" model, to involve them more closely in faculty outreach and support. However, we must acknowledge that many academic subject librarians already bear a significant number and variety of responsibilities, and they may be hesitant at best to be asked to take on more duties. Thus, the Scholarly 
Communications Librarian must strive, in partnership with their subject liaison colleagues, to develop appropriate bridging mechanisms, that is, norms and procedures for when the support of an engaged faculty member will transition from the subject liaison to the scholarly communications expert.

However, an issue may sometimes exist in convincing faculty to engage with any facet of the library concerning scholarship. For example, one participant responded to an open-ended question by commenting that the library seems "redundant" in this area when they are also receiving training at the departmental and college levels. This lucky professor's department might truly be ahead of the curve in providing advanced training for faculty in topics such as research data management, copyright, OA publishing, open licensing, self-archival, journal evaluation, and impact metrics. Alternatively, this individual may be over-estimating their own knowledge and failing to realize how much more there is to learn - in other words, "they don't know what they don't know." Faculty may also simply under-estimate the library's expertise and value-add services with respect to research, particularly if they still maintain a traditional stereotyped view of the academic library as merely a warehouse for books. For example, the State of Open Data 2020 report from Digital Science showed that most researchers would not think of relying on the library if they required help in making data from their most recent research paper openly available; the library ranked above only "Professional 3rd party service" and "I would not require help," while falling far behind top choices such as "Publisher," "Research officelin-house institutional expert," "Colleague," and even "Web-search" (p. 5). Some disconnect is clear between researcher perceptions and the available library skills and services.

If either overestimation of the self or underestimation of the library is at play (or both), the Scholarly Communications Librarian will need to strategize regarding promotion strategies which clarify the benefit to the faculty member of leveraging library services. A budding partnership with the Office of Research and Sponsored Programs (ORSP) will be one key tool in this strategy: through their work with faculty on external grant applications, the ORSP staff have gained unique insight into the struggles and pain points that faculty encounter. The library and ORSP are engaged in discussions about co-sponsoring practical hands-on workshops to target these areas of need; with luck, after a faculty member experiences the benefits of working with the Scholarly Communications Librarian once through an ORSP-sponsored event, they may be more ready and willing to engage again directly.

\section{LIMITATIONS AND FURTHER RESEARCH}

As with most voluntary surveys of this type, the study suffers from the limitation of selfselection bias: the individuals who felt motivated enough to complete the survey may rep- 
resent a skewed sampling of the entire population. Although the respondent population of 179 is a reasonable sample size, responses are not evenly distributed by college, creating limitations when looking at data broken down by college. Additionally, since less than $10 \%$ of faculty responded, these may represent individuals with higher levels of attentiveness to and interest in library initiatives. Expressed interest in services and willingness to engage with the library may also be overestimated due to issues such as social-desirability bias; respondents may have felt inclined to select the most optimistic answers that they thought would be the most well received. Furthermore, while the survey attempted to provide definitions for concepts such as article processing charges (APCs), misinterpretation such as "paying to publish" in a corrupt sense may have affected some users' responses. This issue of misunderstanding the publishing landscape and library jargon may also lend itself to further research exploration.

Another limitation is that the survey only seeks to measure self-perceived knowledge levels, rather than testing actual knowledge levels. In future efforts to build on this survey, the researchers intend to convene small focus groups of faculty and graduate students and employ more direct testing of conceptual and applied knowledge. Further research could also focus on adjunct faculty, clinical faculty, and other non-tenure track positions, since this study did not have enough respondents from these groups to reach significant conclusions. However, they are often overlooked in the literature and would likely benefit from better research support and experience, since some aspire to earn tenure-track positions.

\section{CONCLUSIONS}

This study looked to determine the baseline knowledge of scholarly communications concepts among faculty and graduate students at a D/PU university. This information is helpful in order to assist academic libraries in determining adequate and appropriate services to offer in support of research endeavors. The results of this study show that scholarly communications concepts are important to faculty and graduate students at a D/PU university. Existing knowledge levels vary, as one would expect, by topic and by college, but interest exists for additional knowledge in these areas. In particular, in areas of both open data sharing and openaccess publishing, an apparent lack of knowledge reveals a need for additional professional development and training. Faculty and graduate student awareness of existing scholarly communications resources within the library was relatively high, but additional promotion could be beneficial, specifically targeting colleges with low awareness. Insights gained from this study will help academic libraries at D/PUs better understand the knowledge and preferences of researchers regarding scholarly communication, better provide relevant and helpful educational opportunities, and better promote those opportunities to targeted groups of faculty, graduate students, and colleges with the highest levels of interest and need. 


\section{AUTHOR CONTRIBUTIONS}

Erin Owens: Project administration, Conceptualization, Methodology, Investigation, Formal analysis, Writing —original draft (Literature Review, Methodology, Discussion, Limitations and Further Research), Writing-review and editing, Visualization. Tyler Manolovitz: Methodology, Investigation, Formal analysis, Writing - original draft (Abstract, Introduction, Results, Conclusion), Writing-review and editing. Lisa Connor: Methodology, Investigation, Formal analysis. Stacy Johnson: Methodology, Investigation, Formal analysis, Literature searching.

\section{REFERENCES}

Abrizah, A. (2009). The cautious faculty: Their awareness and attitudes towards institutional repositories. Malaysian Journal of Library \& Information Science, 14(2), 17-37.

Blankstein, M., \& Wolff-Eisenberg, C. (2019). Ithaka S+R US Faculty Survey 2018. https://doi.org/10 $.18665 /$ sr.311199

Creaser, C. (2010). Open access to research outputs-Institutional policies and researchers' views: Results from two complementary surveys. New Review of Academic Librarianship, 1, 4. https://doi.org $\underline{/ 10.1080 / 13614530903162854}$

DeSanto, D., \& Nichols, A. (2017). Scholarly metrics baseline: A survey of faculty knowledge, use, and opinion about scholarly metrics. College \& Research Libraries, 78(2), 150-170. https://doi.org/10.5860 $\underline{\mathrm{crl} 1.78 .2 .150}$

Diekema, A. R., Wesolek, A., \& Walters, C. D. (2014). The NSF/NIH effect: Surveying the effect of data management requirements on faculty, sponsored programs, and institutional repositories. Journal of Academic Librarianship, 40(3/4), 322-331. https://doi.org/10.1016/j.acalib.2014.04.010

Digital Science. (2020). The State of Open Data 2020 (Version 2). https://doi.org/10.6084/m9.figshare $\underline{.13227875 . v 2}$

Gaines, A. M. (2015). From concerned to cautiously optimistic: Assessing faculty perceptions and knowledge of open access in a campus-wide study. Journal of Librarianship \& Scholarly Communication, 3(1), 1-40. https://doi.org/10.7710/2162-3309.1212

Gadd, E. (October 31, 2017). Guest post: Academics and copyright ownership: Ignorant, confused or misled? The Scholarly Kitchen [blog]. https://scholarlykitchen.sspnet.org/2017/10/31/guest-post -academics-copyright-ownership-ignorant-confused-misled/

Graveline, J. D. (January 2010). Debunking common misconceptions and myths. College \& Undergraduate Libraries 17(1): 100-105. https://doi.org/10.1080/10691310903584650 
Hahnel, M. (July 1, 2015). “2015 - The year of open data.” https://figshare.com/blog/2015_The year of_open_data_mandates/143

Harley, D., Acord, S. K., Earl-Novell, S., Lawrence, S., King, C. J., \& University of California, Berkeley, Center for Studies in Higher Education. (2010). Assessing the future landscape of scholarly communication: An exploration of faculty values and needs in seven disciplines; Final Report. https:// escholarship.org/uc/cshe fsc

Jamali, H. R. (2017). Copyright compliance and infringement in ResearchGate full-text journal articles. Scientometrics 112: 241-254. https://doi.org/10.1007/s11192-017-2291-4

Kocken, G. J., \& Wical, S. H. (2013). "I've never heard of it before”: Awareness of open access at a small liberal arts university. Behavioral \& Social Sciences Librarian, 32(3), 140-154. https://doi.org/10 $.1080 / 01639269.2013 .817876$

Laughtin-Dunker, K. (2014). Assessing the scholarly communication attitudes and practices of faculty: Lessons from a "failed" survey. Journal of Librarianship \& Scholarly Communication, 2(3), 1-13. $\underline{\text { https://doi.org/10.7710/2162-3309.1164 }}$

Lercher, A. (2008). A survey of attitudes about digital repositories among faculty at Louisiana State University at Baton Rouge. Journal of Academic Librarianship, 34(5), 408-415. https://doi.org $\underline{\text { 10.1016/j.acalib.2008.06.008 }}$

Lwoga, E. T., \& Questier, F. (2014). Faculty adoption and usage behaviour of open access scholarly communication in health science universities. New Library World, 115(3/4), 116-139. https://doi. org/10.1108/NLW-01-2014-0006

Mischo, W., \& Schlembach, M. (2011). Open access issues and engineering faculty attitudes and practices. Journal of Library Administration, 51(5-6), 432-454. https://doi.org/10.1080/01930826.2011 $\underline{.589349}$

National Academies of Sciences, Engineering, and Medicine; Policy and Global Affairs; Committee on Science, Engineering, Medicine, and Public Policy; Committee on Responsible Science. (2017). "Foundations of integrity in research: Core values and guiding norms." In National Academies of Sciences, Engineering, and Medicine, Fostering Integrity in Research (pp. 27--38). Washington, D.C.: National Academies Press. https://doi.org/10.17226/21896

Peekhaus, W., \& Proferes, N. (2015). How library and information science faculty perceive and engage with open access. Journal of Information Science, 41(5), 640-661. https://doi.org/10.1177 $\underline{0165551515587855}$

Rodriguez, J. E. (2014). Awareness and attitudes about open access publishing: A glance at generational differences. Journal of Academic Librarianship, 40(6), 604-610. https://doi.org/10.1016/j.acalib .2014 .07 .013 
Sutton, S., Miles, R., \& Konkiel, S. Q. (2018). Awareness of altmetrics among LIS scholars and faculty. Journal of Education for Library \& Information Science, 59(1/2), 33-47. https://doi.org/10.3138/jelis $\underline{.59 .1-2.05}$

Thuna, M., \& King, P. (2017). Research impact metrics: A faculty perspective. Partnership: The Canadian Journal of Library \& Information Practice \& Research, 12(1), 1-25. https://doi.org/10 $.21083 /$ partnership.v12i1.3906

Tran, C. Y., \& Lyon, J. A. (2017). Faculty use of author identifiers and researcher networking tools. College \& Research Libraries, 78(2), 171-182. https://doi.org/10.5860/crl.78.2.171

University of California Office of Scholarly Communications. (2007). Report on Faculty Attitudes and Behaviors Regarding Scholarly Communication. https://osc.universityofcalifornia.edu/2007/08/report -on-faculty-attitudes-and-behaviors-regarding-scholarly-communication/

Van Orsdel, Lee. (2007). Faculty Activism in Scholarly Communications Opportunity Assessment Instrument. https://www.arl.org/wp-content/uploads/2007/11/scprog-fac-activism-assessment.pdf

Van Tuyl, S., \& Michalek, G. (2015). Assessing research data management practices of faculty at Carnegie Mellon University. Journal of Librarianship \& Scholarly Communication, 3(3), 1-30. https:// doi.org/10.7710/2162-3309.1258

Vinyard, M., \& Colvin, J. B. (2018). How research becomes impact: Librarians helping faculty use scholarly metrics to select journals. College \& Undergraduate Libraries, 25(2), 187-204. https://doi.org $\underline{10.1080 / 10691316.2018 .1464995}$

Weller, T., \& Monroe-Gulick, A. (2015). Differences in the data practices, challenges, and future needs of graduate students and faculty members. Journal of EScience Librarianship, 4(1). https://doi.org $\underline{10.7191 / \text { jeslib.2015.1070 }}$

Wolff-Eisenberg, C., Rod, A. B., and Schonfeld, R. C. (2015). Ithaka S+R US Faculty Survey 2015. https://doi.org/10.18665/sr.277685 